\title{
Design and implementation of automatic body heat sink for the Hypohidrosis patient.
}

\author{
Tayaba Naz ${ }^{\text {* }}$, Muhammad Atif ${ }^{2}$, Asim Aslam², Aqib Aslam², Faryal Ashraf ${ }^{2}$ \\ ${ }^{1}$ Southeast University, P.R. China \\ ${ }^{2}$ Mehran University of Engineering and Technology, Jamshoro, Pakistan
}

\begin{abstract}
Objective: To give a concept for Designing an Arduino based device for treatment of a sweating disorder for the patient suffering from hypohidrosis and anhidrosis sweating conditions, by using Thermoelectric cooler which follows the principle of Peltier effect.

Methods: The whole system is based on cooling properties of the thermoelectric cooler (TEC), (operating voltage 0-15.2V DC and 0-6A) and temperature sensor LM35 (Operating voltage 4-30 volts) detection. The device operating system is controlled by the Arduino Uno R3 (Operating voltage 5v, Input voltage 7-12 V) programming and powered by a lipo battery. If body temperature exceeds $>37^{\circ} \mathrm{C}$ then Arduino will send signal to relay D2 $\mathrm{V}_{\max }(3.5 \mathrm{VDC}-33.6 \mathrm{VDC})$ to turn on TEC and then TEC start cooling from one side that is attached to the skin and exhales heat from another side by heat sink fan until the body temperature of specific body area under TEC reaches to the normal body temperature.

Results: TEC voltage is inversely proportional to the change in temperature, so when the body temperature increases with respect to atmospheric temperature then TEC voltage decreases which eventually cause an increase in temperature of cooling side of TEC. When TEC voltage is $2.5 \mathrm{~V}$ then the temperature at the cooling side will be $15.5^{\circ} \mathrm{C}$. When TEC voltage is $3.5 \mathrm{~V}$ then the temperature at the cooling side will be $12.5^{\circ} \mathrm{C}$. When TEC voltage is $4.9 \mathrm{~V}$ then the temperature at the cooling side will be $6.8^{\circ} \mathrm{C}$. When TEC voltage is $6.2 \mathrm{~V}$ then the temperature at the cooling side will be $3.1^{\circ} \mathrm{C}$. When TEC voltage is $10.2 \mathrm{~V}$ then the temperature at the cooling side will be $2.9^{\circ} \mathrm{C}$.

Conclusion: This device can be very helpful for treating patients suffering from Hypohidrosis and anhidrosis and with the help of this device patient can go for a normal life.

Significance: This device will be very useful in medical and commercial point of view it will help to cure the sweating disorder and it can provide comfort, practicality, and mobility to the patient. It lowers the body temperature in an efficient way and it is also less expensive and it can be helpful for the preventing heat stroke in summer days, besides treating anhidrosis and Hypohidrosis patient it can be helpful for the people who work in warmer areas.
\end{abstract}

Keywords: Arduino, Anhidrosis, Hypohidrosis, Heat sink, Lipo battery, LCD, Peltier effect, Thermoelectric cooler.

\section{Introduction}

Sweating is the body's way of cooling itself off. Some people are not able to sweat normally because their sweat glands do not function properly; this condition is known as hypohidrosis or anhidrosis [1]. Any abnormality in the ectodermic layer is called ectodermic dysplasia which includes hypohidrotic ectodermic dysplasia [2]. It is a type of malfunctioning in working of sweat glands. When some people have a critical sweating disorder, includes lack of complete sweating in the body is termed as anhidrosis [3] while Hypohidrosis is termed as improper sweating of the body when the patient faces thermal changes. So, both these condition cause dysfunction in the human sweating mechanism. The improper anatomical and biochemical mechanisms of sweat secretion may lead to hyperthermia and malfunctioning of multiple organs in the human systems [4]. It can affect one's entire body, a single area, or scattered areas. The inability of a person to sweat normally can cause overheating. This can lead to heat stroke, which is a potentially life-threatening condition [5]. So these patients will suffer from serious glandular and hormonal disorder and they cannot survive easily during harsh sunny days. As a result, these patients cannot face high temperature and their life is bounded to their homes only. They cannot go outside on hot summer days so the purpose of this motivational research is to provide a device which helps these patients by using thermoelectric cooler based on Peltier effect [6,7]. Hypohidrosis can cause dysfunction of various organs in the human body [7]. It can also cause hyperthermia which finally results in heat stroke and nervous breakdown [8]. This disease 
can affect the entire body, or it can also affect a single area of the body, or it can be spotted in various areas of the body. These patients are unable to adapt physiologically to the heat load and this manifests as malaise, dizziness, palpitations which followed by hyperpyrexia in a hot environment $[9,10]$. There are different condition that causes Hypohidrosis such as Ross Syndrome [11], Psoriasis [12], Skin damage [13] and Drugs [14]. There are some people who have defected gene since their birth and they have inherited a damaged gene which causes their sweat glands to malfunction [15].

There are limited methods for treating the patients suffering from hypohidrosis. Although they can be treated by certain medications like prednisolone and therapy techniques like steroid therapy but both medication and therapies have side effect including muscle weakness, hyperglycemia, hypertension, stomach ulcer. Certain devices are also there which lowers the body temperature up to the certain limit by sending impulses to the patient's body [16]. While the others act as cooling suits [17] and cooling jackets [18,19] but these all devices and medications are not too much applicable to lower the body temperature up to an effective limit [20]. In addition these all devices are restricted to a certain area so we are striving to design a device that will lower down the body temperature in an efficient and more probably the best way. Our motivation is to implement a device that will control the patient's body temperature automatically by sensing environmental and body temperature and making a difference between body and environmental temperature gradient up to predefined values by using the thermoelectric cooler which is based on a phenomenon that whenever a voltage source is connected with its junction then it produces heat flux which causes cooling from on one side and heating from another side of TEC [21]. If body temperature is shooted above the normal range than this device will sense the changing signal and start cooling to the body and lowers the body temperature up to programmed value.

\section{Experimental Method}

The experimental method is based on controlling the hardware components of the device with reference to the Arduino Uno R3 microcontroller (Atmega328P) [21] programming (Figure 1). Arduino Uno R3 is connected with two temperature sensor LM35 [22] one temperature sensor is attached to the patient's skin which monitors body temperature and other sensor monitors the atmospheric temperature. Both temperatures are shown on LCD (LCM1602) [23]. If the temperature of the body is above normal $\left(>37^{\circ} \mathrm{C}\right)$ then this data will transfer to relay, to turn on TEC and the cooling process starts up to predefined values of temperature which are already set through Arduino programming. The whole circuit is powered by a lipo battery [24]. In the cooling process, the thermoelectric cooler $[25,26]$, creates a temperature difference on its two sides, the cool side is placed on the body that will transfer the cooling temperature to the body and the excessive heat is ejected out through another side of the device by the heatsink fan. This heatsink is attached the hot side of the thermoelectric cooler that sinks the excessive device heat (Figure 2).

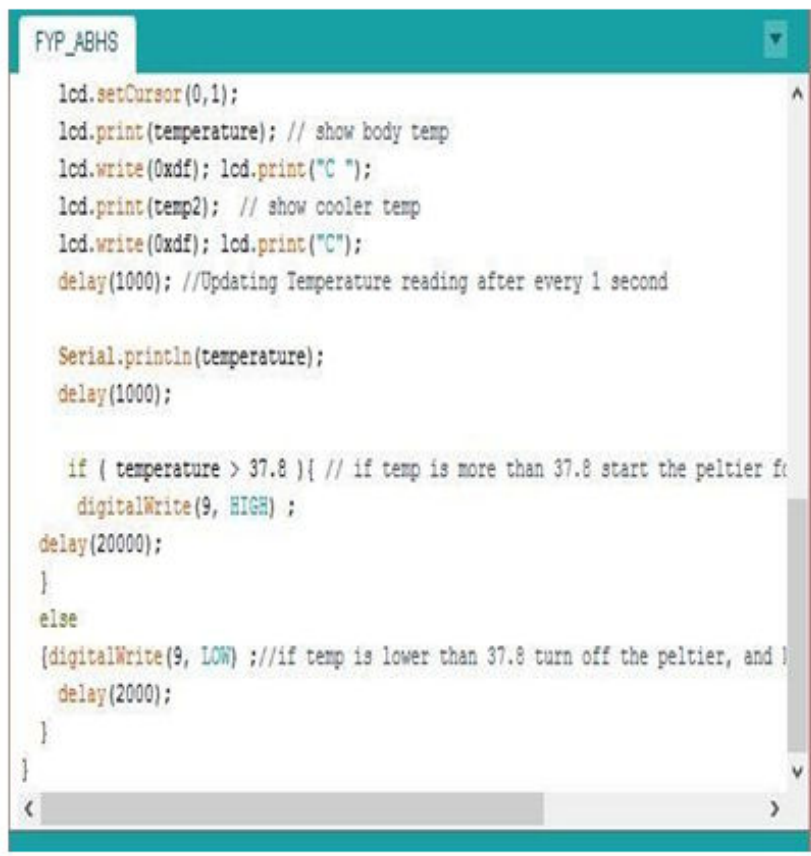

Figure 1: The Arduino programming for TEC to maintain pre defines body temperature value.
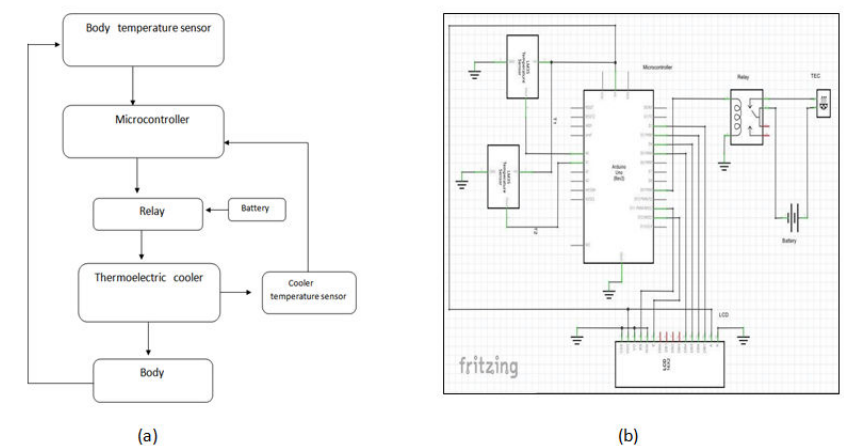

(b)

Figure 2: Schematic diagram of the experimental setup and system design A: The circuit diagram of connected hardware components. B: working flow chart of system working principle.

\section{Results and Discussion}

TEC voltage is inversely proportional to the change in temperature, so when the body temperature increases with respect to atmospheric temperature then TEC voltage decreases which eventually cause an increase in temperature of the cooling side of TEC. When TEC voltage is $2.5 \mathrm{~V}$ then the temperature at the cooling side will be $15.5^{\circ} \mathrm{C}$. When TEC voltage is $3.5 \mathrm{~V}$ then the temperature at the cooling side will be $12.5^{\circ} \mathrm{C}$. When TEC voltage is $4.9 \mathrm{~V}$ then the temperature at the cooling side will be $6.8^{\circ} \mathrm{C}$. When TEC voltage is $6.2 \mathrm{~V}$ then the temperature at the cooling side will be $3.1^{\circ} \mathrm{C}$. When TEC voltage is $10.2 \mathrm{~V}$ then the temperature at the cooling side will be $2.9^{\circ} \mathrm{C}$. When TEC voltage is $12 \mathrm{~V}$ then the temperature at the cooling side will be $2.5^{\circ} \mathrm{C}$ (Table 1 ). The time taken by TEC for producing cooling effect depends on applied voltage 
when the voltage is high then cooling effect time decreases mean TEC provide more cooling in a shorter period of time when the applied voltage gradually increases (Table 2). While making the device there could be certain troubleshooting which is listed in Figure 3.

Table 1: The TEC temperature and power consumption with reference to different voltages.

\begin{tabular}{|c|c|c|c|c|c|}
\hline Test & TEC voltage (V) & TEC current (A) & Heat sink hot temp $\left({ }^{\circ} \mathrm{C}\right)$ & Cold temp $\left({ }^{\circ} \mathrm{C}\right)$ & TEC power (W) \\
\hline 1 & 2.5 & 0.68 & 27.9 & 15.5 & 1.7 \\
\hline 2 & 3.5 & 0.95 & 28.3 & 12.5 & 3.32 \\
\hline 3 & 4.9 & 1.35 & 29.2 & 6.8 & 6.61 \\
\hline 4 & 6.2 & 1.84 & 31.7 & 3.1 & 11.4 \\
\hline 5 & 10.2 & 3.25 & 38.8 & 2.9 & 33.15 \\
\hline 6 & 12 & 3.27 & 3.27 & 2.5 & 39.24 \\
\hline
\end{tabular}

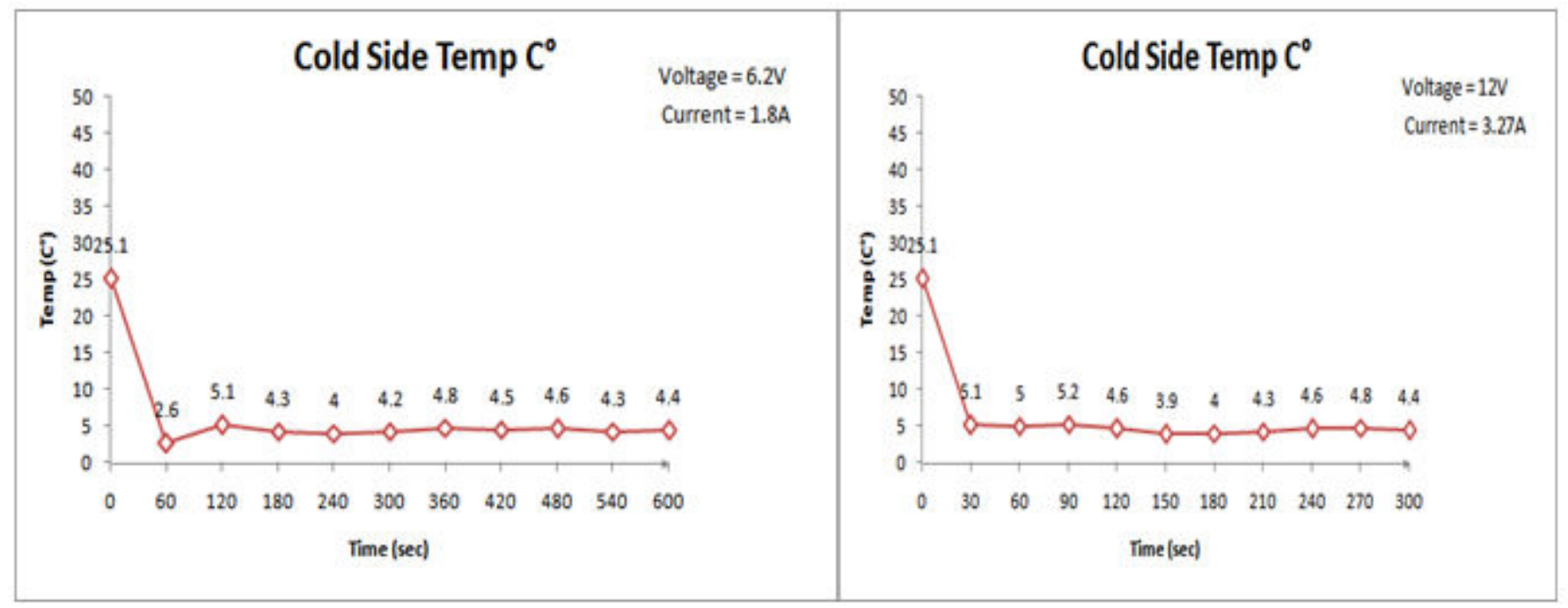

Figure 3: The Cold temp of TEC and cold temp of TEC at $12 \mathrm{~V}$ (shows a graphical representation of the cold side temperature of TEC with respect to time and applied voltage showing Cold side temp of TEC at $6.2 \mathrm{~V}$ and cold side temp of TEC at $12 \mathrm{~V}$ ).

Table 2: The possible problems which we can face while making this system and their solutions.

\begin{tabular}{|c|c|c|c|}
\hline S No. & Possible problems & Causes & Solutions \\
\hline 1 & Display is not showing on LCD & The connection is loose or battery is low & Check battery voltages and LCD connections \\
\hline 2 & TEC is not working properly & Loose connection or low voltage & Check the connections and voltage $f$ battery \\
\hline 3 & Cooling system is not operating & Damaged relay & Replace relay \\
\hline 4 & Low cooling at TEC & Loose connection of heat sink fan & Check the connections \\
\hline 5 & System got shutdown & Voltage and current rating & Check the ampere and voltage reading \\
\hline
\end{tabular}

\section{Conclusion}

This device can provide comfort, easiness coupled with mobility. It is also affordable and this device lowers the body temperature in an efficient way and can be helpful for the purpose to cure Hypohidrosis. Subsequently, it will lower the body temperature according to environmental temperature. But there is also some future suggestion for making this device more compatible to use by patients by compacting the device size and also it can use the body's excessive heat as energy to operate the device. Moreover, wireless based technology can be incorporated for a consultant to monitor the patient's body temperature. 


\section{References}

1. Arcas J, Ferrer T, Roche MC, Bermejo AM, Martín VL. Hypohidrosis related to the administration of topiramate to children. Epilepsia 2001; 42:1363-1365.

2. Deshmukh S, Prashanth S. Ectodermal Dysplasia: A Genetic Review. Int J Clin Pediatr Dent 2012; 5:197-202.

3. Thabusum AN, Sudhakarareddy RR, Ramesh T. Ectodermal Dysplasia-A Case Study of Two Identical Sibilings. International Journal of Dental Sciences and Research 2014; 2:175- 178.

4. Barrera NM, Jiménez NM, Candau L, Portal RDL. Anhidrosis and hyperthermia associated with treatment with topiramate. Rev Neurol 2002; 34:114- 116.

5. Rachel Nall, RN, BSN, CCRN. Hypohidrosis (Absent Sweating) 2017.

6. Nikam AN, Hole AJ. A Review on use of Peltier Effects. IJSSBT 2014; 2:2.

7. Peltier effect (Physics) Encyclopedia Britannica, Dec 2013.

8. William P, Cheshire Jr, Fealey RD. Drug-induced hyperhidrosis and hypohidrosis. Drug Safety 2008; 31:109-112.

9. Chia KY, Tey HL. Approach to Hypohidrosis J Eur Acad Dermatol Venereol 2013; 7:799-804.

10. http://www.healthhype.com/anhidrosis- and-hypohidrosisno-sweating-and-low- perspiration.html\#prettyPhoto

11. Thami GP, Kaur S, Kanwar AJ. Acquired idiopathic generalized anhidrosis: a rare cause of heat intolerance. Clin Exp Dermatol 2003; 28:262-264.

12. Coulson IH. Disorders of sweat glands. In: Burns T, Breathnach S, Cox N, Griffiths C, editors, Rookís Textbook of Dermatology 2004; 45:14-45.

13. http://www.rightdiagnosis.com/sym/hypohi drosis_in_children.html.

14. Canel L, Zisimopoulou S, Besson M, Nendaz M. Topiramate- induced severe heatstroke in an adult patient: a case report. J Med Case Rep 2016; 10:1.
15. http://www.mayoclinic.org/diseases-

conditions/ anhidrosis/basics/causes/con- 20033498

16. http://www.cnet.com/news/regulate-your- bodystemperature-with-this-wearable-bracelet

17. Sabarish CH, Reddy RS. Solar Powered Thermal Jacket for Soldiers in Extreme Temperatures. International Journal \& Magazine of Engineering, Technology, Management and Research 2015; 2: 2348-845.

18. http://www.ehealthme.com/quick_search/hypohidrosis.

19. Hemavani K, Saikumar V, Jilani SAK. Temperature Programmable Suit using Thermoelectric Cooler/Heater. International Journal of Electronics and Communication Engineering 2015; 2.

20. Saqib MY. Thermoelectric Refrigerator FYP. 2014:4.

21. https://www.arduino.cc/en/Main/ArduinoBoardUno.

22. National Semiconductor Corporation. LM35 datasheet, precision centigrade temperature sensors, Atmel data book 2000 .

23. Liquid crystal display. LCM1602C Datasheet PDF $-16 \times$ 2 LCD display 2017

24. Schalkwijk WV, Scrosati B. Advances in lithium-ion batteries. Kluwer Academic/Plenum 2004.

25. Reiyu C, Guanmin H. Thermoelectric cooler application in electronic cooling. Appl Therm Eng 2004; 24:2207-2217.

26. Wang XD, Huang YX, Cheng CH, Lin DTW. A threedimensional numerical modelling of thermoelectric device with consideration of coupling of temperature field and electric potential field. Energy 2012. 47:488- 497.

\section{Correspondence to:}

Tayaba Naz

Southeast University

P.R. China 